\title{
Destination online communication: why sometimes less is more. A study about online communication of English destinations
}

Article

Accepted Version

Inversini, A., Cantoni, L. and De Pietro, M. (2014) Destination online communication: why sometimes less is more. A study about online communication of English destinations. Journal of Travel \& Tourism Marketing, 31 (5). pp. 563-575. ISSN 15407306 doi: https://doi.org/10.1080/10548408.2014.883949 Available at https://centaur.reading.ac.uk/75370/

It is advisable to refer to the publisher's version if you intend to cite from the work. See Guidance on citing.

To link to this article DOI: http://dx.doi.org/10.1080/10548408.2014.883949

Publisher: Informa UK Limited

All outputs in CentAUR are protected by Intellectual Property Rights law, including copyright law. Copyright and IPR is retained by the creators or other copyright holders. Terms and conditions for use of this material are defined in the End User Agreement. 


\section{CentAUR}

Central Archive at the University of Reading

Reading's research outputs online 


\title{
Destination Online Communication: Why Sometimes Less is More.
}

\section{A Study about Online Communication of English Destinations.}

\begin{abstract}
This research investigates the relationship between website design and website end-user experience of a vast number of English Tourism Destinations, both local regional and regional. Following recent research in the field, this paper evaluates destinations online communication based on the implemented website features and on the effectiveness of the communication itself, borrowing its research methodology from different domains. After a content and functionality analysis, a user experience scenario-based investigation has been carried, which demonstrated that complex destination websites are not always serving end-users' needs properly, or - in other words - that website complexity is not directly related with good user experience. Having less contents and functionalities, but clearly user-oriented, may help destination managers to foster their online communication.
\end{abstract}

Keywords: DMO online communication, Destination Management Systems, Online Communication.

\section{Introduction}

The importance of online communication for tourism destination marketing and commerce has been acknowledged by several scholars in recent years (e.g. Buhalis, 2003; Wang and Fesenmaier, 2006). In fact tourism is one of the domains where the impact of new technologies has actually revolutionized the industry (e.g. Buhalis and Spada, 2000; Gretzel et al., 2000): the intrinsic characteristics of tourism, such as its information intensity (Poon, 1993), has made it the ideal field for technology exploitation and evolution. Technology, and especially the internet, enables a fast information exchange between service providers and end-users, thus fully supporting tourism business models (Werthner and Klein, 1999). Private tourism companies (often Small and Medium Enterprises) are not the only beneficiaries of this technological (r)evolution in tourism (e.g. Murphy et 
al., 2003; Law et al., 2006). Tourism Destination Management Organizations (DMO) also got advantage from technologies (Buhalis, 2000): the advent of the so-called Destination Management Systems (DMS - Horan and Frew, 2007) allowed destinations to better manage communication flows internally, and marketing and selling flows externally (Frew and O'Connor, 1999), eventually doing also market research. Thanks to DMS, destinations are acting as communication hubs (Inversini and Cantoni, 2009) connecting internal stakeholders with the external world. Major destinations (e.g. Inversini et al., 2012) are more and more shifting promotional budget from previous promotional channels (such as printed leaflets, fairs etc.) to the online environment, producing complex websites with a variety of contents and functionalities that might serve prospective travellers as well as a vast range of other stakeholders. Destination managers are aware of the complexity of the online environment, but do not pay always enough attention to the possible experience of end-users accessing the website with a specific goal in a specific environment (ISO 9241-11).

This paper investigates the following two aspects: (i) on the one side the complexity in terms of contents and functionalities of a number of English Destinations websites, (ii) on the other side the user experience of prospective tourists, which may access those websites. Results show that in some of the considered cases having less content and functionalities, but well-designed and user-oriented, may help in better serving possible target groups.

\section{Literature review}

\section{$\underline{\text { Tourism and ICT }}$}

The advent of new media in the tourism field has dramatically changed tourists' behaviour, allowing them to have direct access to a much greater amount of information and consequently increasing the number of possible choices and options (Mills and Law, 2004; Buhalis and Law, 2008). According to Buhalis (1998), present tourists are more independent and sophisticated in their travel planning activities, using several channels and tools to identify, customize and purchase tourist products. These channels include among the others online travel 
agencies, search engines, destination management systems, social networks and other web2.0 websites, as well as price comparison sites and intermediaries' sites. In the present information-overload era (Inversini et al., 2009); the most successful players are those who are able to continuously provide high quality information and identifying customers' needs (Buhalis and Law, 2008; Choi et al., 2007). Nowadays Information and Communication Technologies (ICTs) have a key role in determining the competitiveness of the tourism industry, providing tools to support in an effective way the development, management and distribution of the offers on the global market as well as the interaction with consumers (UNWTO, 2001; Buhalis, 1998; Buhalis, 2003). Direct dialogue with customers, actual ones and prospects, is enabled in a cost-effective way by the internet, which assists tourism suppliers to use a wide range of online promotional activities to integrate, if not substitute, offline promotions (Gretzel et al., 2000; O'Connor \& Frew, 2004). As a matter of fact, the internet is one of the most relevant technologies affecting the tourism sector (Buhalis, 1998); according to Cantoni and Tardini (2006) it has a clear competitive advantage with respect to other mass media, in terms of: (i) multimedia (use of different type of media such as text, audio, picture, video), (ii) interaction (high level of interactivity), (iii) persistence (information can be easily archived), (iv) in-depth studies (online publishing), and (v) immediacy (information can be easily updated). Information and Communication Technologies (ICTS) and the internet have deeply changed the way business is conducted in the tourism sector (Buhalis and Law, 2008); consequently, tourism businesses and organizations are putting growing efforts in developing and improving their online presence and online communication with customers and potential customers.

In this context, it becomes important the issue of online information search (Jang, 2004), which is attracting the interest of academics and practitioners as a major trends within the travel and tourism field. The main issue related with information search is the possibility of locating the correct and relevant travel and tourism information in the so called "online tourism domain" (Xiang et al., 2008), the online space that can be accessed from the users' preferred gate to the internet: search engines. Within the overwhelming amount of web pages that can be retrieved in the online tourism domain, Destination Management Organizations' websites play a key 
role in helping prospective travellers to locate the correct, pertinent and accurate information. Destinations' websites should be used by customers as source of information, thus they should be designed to match end users' needs and expectations.

\section{Destination Management Organizations}

Destination Management Organizations (DMO) are increasingly using ICTs and exploiting the potentials of the internet to facilitate users' experience when approaching the destination in the online environment (e.g. Gretzel et al., 2006). One of the key channels used by a DMO is its official website. Choi, Lehto and Oleary (2007), as well as Wang (2008) state that DMOs use official destinations' websites to provide users with information during the three phases of tourism goods consumption, and consequently promote the destination image. However, the simple broadcasting of information is not enough, and creating occasions for interaction and participation on the website is key (Doolin et al., 2002). Besides the users' need for quality information, and the importance of effective interaction, there is another factor that DMOs must take into consideration: information needs change along the vacation planning process, since it is very dynamic and deeply influenced by personal knowledge, personal features, and tasks (Pan and Fesenmaier, 2006). According to Gretzel et al. (2006) the tourist experience is characterized not only by a consumption phase - the real trip and experience at the destination - as any other product or service, but by extensive pre- and post- consumption phases as well: the pre-consumption phase is dedicated to the planning of the actual trip, while the post-consumption phase is dedicated to sharing and reexperiencing activities. It is therefore clear how the use of Information technologies is extended to all the stages of the tourist experience. In this complex context, DMOs are vigorously working on their online communication (Wang, 2008), improving contents and functionalities to support consumers all along the tourist experience, from information search and booking, to mobile technologies to be used en route, and newsletters, forums and other sharing opportunities once the physical experience of the trip is over (Choi et al., 2007). 
A recent case study by Inversini, Brüllart and Cantoni (2012) about the online communication of the Swiss Tourism Board highlighted, on the one side, the complexity of the website of one of the most popular destinations in Europe, particularly describing the technological architecture and its evolution but also the growth of the regional (i.e. Cantonal) destinations' commitment towards technologies. On the other side, analysing the strategy reports of the destination it was clear the shifting that destinations are experiencing: promotional budget is being conveyed to the online environment realizing a media-convergence of the majority of marketing activities. What is clear from this case study is that destinations websites are not mere technological artefacts (Inversini, 2011), but complex communication instruments that impact on several levels (i.e. from destination management, to destination promotion and commercialization). Internet and the online channels allow tourism organizations and companies to engage consumers' interest and participation, and capture key information (Wang and Fesenmaier, 2006); moreover, websites contents are crucial since they highly influence users' perception about company or, broadly, about the tourism destination (Doolin et al., 2002). It is therefore not possible to consider websites only as technological tools that are an exclusive responsibility of engineers (Van der Geest, 2001): websites are an essential part of a company external and internal communication (e.g. Pan and Fesenmaier, 2000), and technical competencies alone are not sufficient to achieve quality online communication (van der Geest, 2001); on the contrary, running a website means considering various dimensions and consequently employing several competencies and skills.

Cantoni and Tardini (2006) stated in their Website Communication Model (WCM) that a website can indeed be considered as a cluster of: (i) contents and services (the actual contents and functionalities of the website); (ii) accessibility tools, which make the contents and services available (hardware, software, and visual interface); (iii) people who manage (people in charge of projecting, producing, maintaining, promoting, evaluating and improving the website as well as interacting with users); (iv) users/clients (people accessing the website and enjoying its contents and services). As it is possible to note, the first two pillars are things, while the third and fourth pillars refer to people. Project and evaluation are considered as cross-pillars, indicating that the WCM can 
be used for both the project phase and evaluation phase of a website. A last key element of the model is the context: it is not possible to consider the 4 pillars as isolated, but it is necessary to study them as part of a context, of the external world which influences and affects them.

\section{$\underline{\text { Tourism website evaluation }}$}

Travel website evaluation studies have become extremely important to both industrial practitioners and academic researchers thus creating a body of literature that have been summarized and rationalized by different research papers (e.g. Law et al., 2010; Morrison et al., 2004; Ip et al., 2011). These researches examine the issues of tourism website evaluation categorizing the methodologies used into qualitative and quantitative evaluations (Law et al., 2010); furthermore in a recent study Ip, Law and Lee (2011) classified the studies into (i) evaluation by phases, based on functionality layers that a user encounters while navigating a website, (ii) evaluation by features, based on the analysis of website content, design and even content $\&$ design, (iii) evaluation by features and effectiveness, based on the analysis of features and user satisfaction evaluation. One of the interesting aspects of the work by Ip, Law and Lee (2011) is that they overcome the distinction among qualitative and quantitative evaluation methodologies, and provide a more convincing perspective on these studies. Lastly, a recent research by Morrison, Taylor and Douglas (2004) discussed the possible parameters and methodologies to be used while evaluating websites in the travel and tourism domain, presenting different experiences and case studies, and conceptualizing the idea of applying economics concepts to website evaluation (such as the Balance Score Card). This approach has been then proposed also by Stepchenkova, Tang, Jang, Kirilenko and Morrison (2009), which evaluated Convention and Visitors Bureaus' websites based on spatial and structural patterns: subsequently, Lee and Morrison (2010) used the method of the Balanced Score Card to evaluate hotel website performances. While proposing the balance score card methodology, Morrison, Taylor and Douglas (2004) also predicted that benchmarking activities will be a major approach for future tourism and hospitality website evaluation; authors underline the fact that comparative analytical tools will be more and more used in the field 
to check one or more websites against competitors in the same (or even in a different) market/domain (Morrison et al., 2004; Law et al., 2010).

It is worthy to mention that to date on the one side, no researches focused this particular relationship between contents and functionalities and user experiences for understanding communicative and design issues, and on the other side there are no studies focusing on the analysis of English Destination Websites online communication (Ip et al., 2011).

\section{Research Design}

The main objective of this research is to analyse English tourism destinations' online performance and capability to satisfy users' information and communication needs. Following recent research in the field (e.g. Morrison et al., 2004; Law et al., 2010), and especially the one by Ip, Law and Lee (2011), which analysed Website Evaluation Studies in the Tourism and Hospitality field from 1996 to 2009, this research analyses the destinations' online communication "by features and effectiveness" (Ip et al., 2011, pp. 253), underlining the website characteristics and peculiarities, harvesting and counting contents and functionalities (Murpy et al., 1996) as well as anticipating users' experience (Essawy, 2006). The methods used are a content analysis (content and functionalities assessment, related to "evaluation by features"), and a scenario-based expert evaluation (user satisfaction, "related to effectiveness"). Both methods have been already used successfully in the travel and tourism domain, but no paper to date has mixed them in order to get insights on the relationship between website complexity and satisfying user experience.

As regard previous research in the field, the work by Ip, Law and Lee (2011) on tourism website evaluation was considered as a starting point due to its detailed review of evaluation methodologies and of their results. Furthermore, the work by Choi, Lehto and Oleary (2007), as well as the work by Wang (2008) were considered as the basis for the analysis of contents and functionalities, as well as for the analysis of user experience. The two different methods chosen to serve the analysis by features and effectiveness are here presented: the first 
one, is a common methodology analysis within the communication domain already used in the online communication environment: namely content analysis (e.g. Inversini, 2011); the second one is a common methodology used in Human Computer Interaction (e.g. Dix et al., 2004) and Usability (e.g. Triacca et al., 2005), based on severity ranking (Nielsen, 2006) of users' scenarios (Carroll, 2000). It is worth to mention here that usability assessment has been used in tourism as strategy to assess destination websites (e.g. Qi et al., 2008, Essawy, 2006).

\subsection{Research Questions and Methods}

In order to pursue the main research objective - i.e. analyse English tourism destinations' online communication and capability to satisfy users' information and communication needs - two research questions have been elaborated:

RQ1. Is there an informative core, or, in other words, a well defined set of contents and functionalities that characterize English Destination Websites?

RQ2. Having more contents and functionalities, does this mean having a better user experience?

As mentioned above, the methods used to investigate the research questions are: (i) content and functionality analysis, and (ii) scenario-based evaluation.

\section{Content and functionality analysis}

The content and functionality analysis allows to detect and map the contents and functionalities of a website, and to investigate its level of completeness (Cantoni et al., 2007): it is performed using a so-called contents and functionalities grid (e.g. Inversini, 2011), featuring a list of indicators, each one representing a single type of content or functionality that is relevant for the domain. Starting from relevant literature review in the field (e.g. Choi et al., 2007; Wang, 2008), which highlighted destination website characteristics, peculiarities and functions, and from previous content analysis works in the field (Cantoni et al., 2007; Lizzi et al., 2011), a bottom-up analysis 
grid was created to investigate destinations' online communication field. The analysis grid has been created iteratively by analysing all the websites in the sample. Each and every time a new type of content or functionality was found, it was added to the grid and the sample re-analysed.

For the present research a contents and functionalities grid with 189 indicators has been used. Indicators could be understood as types of contents and/or functionalities that compose the website (Cantoni et al., 2007). The analysis was carried out visiting each website in the sample and filling the grid acknowledging the presence or absence of an indicator. Value 1 was assigned when the indicator, and consequently the piece of content/functionality associated with it, was available on the website; value 1 was also attributed when there was an external link giving the precise information (e.g. a link to a weather forecast website showing directly on the landing page the weather forecast for the destination in object). Value 0 was assigned when the piece of information or the functionality was absent, or when the external link pointed to a generic website (e.g. for ticketing and timetables of the local bus company, the link points to the homepage of the bus company, where the user needs to perform a research to retrieve the desired information).

The indicators were ex-post organized into six macro areas, which follow a communicative/narrative model. The macro areas have been qualitatively created after all the indicators were collected and indicators were grouped on a mutually exclusive principle. The areas are below described:

1. There is a place: the first macro area contains indicators related to geography, history, and local culture of the destination. Indicators in this macro area give a general introductory knowledge about the destination as a physical place;

2. Where you can go and stay: the second macro area presents indicators concerning the practical organization of a tourism experience, such as transportation, accommodation, itineraries and practical information; 
3. And enjoy doing something: the indicators in this macro area are related to attractions, eating and drinking and general entertainment;

4. In a given period of time: the fourth macro area concerns indicators related to events and seasonal tourism;

5. That's me (DMO) which is suggesting you to come: the indicators contained in this macro area refer to contents about the DMO itself: presentation, contacts and services;

6. General services: the last macro area contains indicators related to additional services and functionalities offered by the website, such as online shop, site map, FAQs, reviews submission, website personalization, translations, etc.

Indicators in a macro area were then sub-divided into areas, for a total of 28 areas. Figure 1 shows the grid organization: (i) macro area: first level of granularity and narration, (ii) area: second level of granularity, (iii) indicators: last level of granularity, (iv) website to be analysed, (v) indicators labeled according to the presence/absence.

\section{[FIGURE 1]}

\section{$\underline{\text { The scenario-based evaluation }}$}

The scenario-based evaluation is a common technique used in Human Computer Interaction (e.g. Dix et al., 2004) for website design and evaluation, which describes how a website would be possibly used by specific users in specific situations; it is performed completing actions, which represent typical and/or significant activities, taking into account the level of satisfaction of the user when interacting with the website (Brinck et al., 2002; Triacca et al. 2005; Carroll, 2000). The evaluation is carried out through an expert severity rating of the scenario of use. According to Carroll (2000), scenarios are stories about users and their situations of use and have basically three elements: (i) a setting or a context of use, defining location and situation of use, (ii) agents or actors: a scenario can include different actors, and (iii) goals or objectives, often implying sub goals or tasks. This research has 
adopted 17 user scenarios, each one composed by: (i) one user profile (ii) one goal: the main objective of the user when navigating the website, (iii) and a set of tasks: operations to be accomplished in order to achieve the given goal. A semi-structured interview with tourism expert Richard Veal, managing director of New Mind (UK market leader for DMO websites), allowed to validate 9 user profiles and 17 scenarios, which can be considered realistic and able to cover most of contents and functionalities that can be found on a tourism destination website.

The scenario-based evaluation was performed on a sample of websites. Starting from the results of the Contents and Functionalities analysis, it was decided to select those destinations placed in the first 30 positions of the Contents and Functionalities ranking. Those websites are the one with the highest number of indicators, thus from a frequency point of view they are the most completed websites. Using the 30 websites with the highest number of indicators is enough to demonstrate RQ2 that is the relationship with the high number of contents and functionalities and user experience. The scenario-based evaluation was performed navigating the website and completing - or attempting to complete - actions and tasks to reach the given goals. A severity rating scale (Nielsen, 2006) was adopted to rank scenarios: the possibility to perform a task is evaluated on a 3-points scale where: " 0 " was assigned when it was not possible to complete the given task; " 0.5 " was assigned when it was partially possible to complete the task; " 1 " was assigned when it was possible to complete the task. The feasibility of a goal derives from the feasibility of the tasks it is composed of. The performance of a destination's website in the scenario-based evaluation depends on the performance of the destination itself in each scenario and, consequently, in each goal.

\section{Sample}

The research sample was selected using the English national DMO website (www. enjoyengland.com): among the whole list of English destinations promoted, only those having an official tourism website have been selected, for a total of 120 destinations (January 2011). The sample includes 53 single city/town destinations (e.g. London, 
Chester, Bath, etc.), and 67 broader destinations: districts, counties, and regions (e.g. Somerset, Devon, North East England, etc.). The analysis was performed in 2011 (January-March).

\section{Results}

$\underline{\text { Results of the contents and functionalities analysis }}$

The contents and functionalities analysis was performed to investigate the level of completeness of English destinations' official tourism websites, and the frequency of relevant contents and functionalities. The 6 macro areas of indicators are ranked according to the frequency of their indicators in the whole sample of 120 destinations.

The macro area named "And enjoy doing something", which comprises indicators related to tourist attractions, tourist activities, and catering providers, is in the top position, with $40.8 \%$ of frequency within the sample. The macro area "There is a place", which includes indicators related to geography, history, and local culture, follows at a short distance (40.3\%). Following are the macro areas "In a given period of time" (40\%), which pertains to events and seasonal tourism, and "Where you can go and stay" (39.2\%), which is devoted to transportation, itineraries, and accommodation. Indicators for contents about the DMO are contained in the "That's me" macro area, with $32.8 \%$ frequency, while "General services" occupies the last position, with $28.8 \%$.

Without considering macro areas, single indicatorsranked as follows (Table 1)

\section{[TABLE 1]}

The most frequent indicators in the macro area "There is a place" are "Destination map", "Destination description", "Cultural/historical places", "Main cities/places", and "Information about the natural environment", which are present in more than $92 \%$ of destinations' websites. In regard to the second macro area devoted to accommodation and travel to the destinations, the indicators listed as "Hotels", "List of 
accommodation", "Grading", "Apartments" and "Bed \& Breakfast" are the most present, with more than 95\% frequency.

Table 1 shows that the vast majority of websites (99\%) in the sample use the indicators "Places of interests", and "List of attractions", while, concerning events and seasonal tourism, the most frequent indicators are "List of events" (96.7\%), "News/what's on", "Event search functionality", "Cultural events", and "List of venues” (93.3\%). In the "That's me" macro area, which presents contents and functionalities about the DMO, "Contacts list", "Addresses and maps", "List of tourist offices", "Web contact" and "About us" turned out to be the most recurring indicators; among the general services offered by websites, the "Internal search engine" is used by 73.3\% of the websites, followed by "Accessibility statement", "Website map", "Guides download" and "Brochures download functionality".

In the category of UGC-related indicators, the indicator "Link to social network official page" (i.e. Twitter and/or Facebook) prevails with $41.7 \%$ of destinations using it; on the other hand, forums have a $0 \%$ presence... The remaining indicators do not go beyond 11\%: link to Official YouTube channel and the official blog of the destination are present in $11.7 \%$ and $10.8 \%$ respectively, while indicators related to consumer reviews are only used by $4.2 \%$.

Concerning the category of online booking-related indicators, more than half of the destinations (57.5\%) provide an accommodation online booking functionality, while attractions and events ticketing functionalities are used by $10 \%$ of the sample; tour ticketing and booking is provided by $8.3 \%$ of destinations. Text contents are prevailing in the category Multimedia-related indicators $(68.3 \%$ for "Brochure download", and $70.8 \%$ for "Guides download"). Picture galleries and videos are used by respectively $36.7 \%$ and $28.3 \%$ of destinations, while the indicator related to audio contents in the form of Podcasts is present on $15 \%$ of studied websites. The least used indicator is "Virtual Tours", appearing in just 4.2\% of the cases. The category Personalization-related indicators shows in the top position the indicator "Suggestions and guides for families", with $56.7 \%$ of destinations using it. 
It is followed by three indicators appearing in more than $40 \%$ of destinations websites related to information for groups (41.7\%), Meeting \& Incentive tourism (43.3\%), and disabled visitors (48.3\%). The less common indicators are "Suggestions and guides for LGBT market" with 7.5\%, and "Studying here tips" for students, with 1.7\%.

\section{$\underline{\text { Results of the scenario-based evaluation }}$}

As stated in the methodology, after the contents and functionality classification only 30 websites (the ones with high ranking) were considered for the qualitative scenario based evaluation. These 30 websites were checked against the scenarios (especially goals and tasks feasibility are here presented).

Concerning the feasibility of goals, the goal with the highest feasibility in the sample of destinations is "Get maps and guides", with $87.74 \%$ of feasibility within the sample; it can then be observed that the Top 5 goals have a feasibility higher than $70 \%$ within the sample, and are related to "Food and Drink" ("Find restaurant where to eat typical Indian food", 70.97\%), general information about the destination, such has destination overview, history, and how to get there and move around (71.77\%), attractions ("Obtain attractions information and book tickets", 75.22\%), and accommodation ("Find and book a Hotel”, 86.18\%). The lowest position is occupied by the goal "Obtain information about surrounding areas", with $27.02 \%$ feasibility, suggesting a tendency in the online communication to consider a destination as an isolated entity or in competition with neighbouring destinations. It is preceded by the goal "Experience recall" with a feasibility of about 30\% (Figure 2).

\section{[FIGURE 2]}

It was then possible to identify the single tasks with the highest feasibility: the top position is shared by three tasks concerning retrieving basic information about accommodation ("Find hotel contact information"), events ("Find ticketing information"), and activities ("Find venue contact information"); those 3 tasks can be totally completed in the whole sample of 31 destinations. Tasks which are related to listing and filtering products by type ("Find the list of the attractions", "Find attractions by type", "Find the list of the events", "Find cultural 
events"), and gathering information about restaurants and accommodation ("Find hotel information", "Find contact information - restaurant"), have a very high feasibility as well.

During the evaluation, several tasks were impossible to be performed in 29 destinations' websites out of 31 . Those are related to retrieving information about surrounding areas and excursions, finding restaurants' menus, special offers devoted to couples, and downloading the calendar of events.

\section{Discussion}

The contents and functionalities analysis allowed to rank the destinations in the sample according to the level of completeness of their official tourist website. London was the most complete website in the sample with 138 indicators out of 189 , corresponding to $73.02 \%$. The Top 5 ranking included four single city destinations (London, Blackpool, Brighton, Bath), and one county (Lancashire). Two city destinations (Kenilworth and Rugby) shared the lowest position with less than $12 \%$ indicators (22 indicators out of 189). As regards research question 1 (RQ1) it was possible to define an informative core which is based on three main issues: (i) destination attractiveness (e.g. places of interests, attractions, activities, things to do and events, cultural and historical places), (ii) destination accommodation facilities (e.g. list of accommodations), and (iii) mobility issues (destination map, destination descriptions), occurring in most of the websites (from 99.2\% to 93.3\%, threshold 90\%).

Furthermore, as stated in the methodology section of the study, the scenario-based evaluation was performed on a reduced sample of destinations, namely those placed in the first 30 positions of the contents and functionalities analysis' ranking, that were the most complete in terms of contents and functionlities. Nevertheless, it was possible to compare the ranking of the scenario-based evaluation with the ranking of the contents and functionalities analysis (first 30 positions). The contents and functionalities analysis assessed the completeness of DMOs' website in terms of offered information and functionalities, while the scenario-based evaluation verified whether those contents (and, in general terms, the websites) are suited for the fulfillment of online goals. 
The contents and functionalities analysis does not provide in itself a quality evaluation, therefore a website that performs well in the contents and functionalities analysis is not implicitly performing the same in the scenariobased evaluation: a content might be present, but it could be not easily accessible or a functionality might be not working properly. Comparing the results of the contents and functionalities analysis with those of the scenariobased evaluation it is possible to investigate the use destinations are making of their online contents and functionalities. A different degree of importance was given to the scenarios starting from the work of Choi, Lehto and Oleary (2007).

[TABLE 2]

Table 2 highlights the differences between the two rankings: in the Top 5 several changes occurred, with only Blackpool (moving to the first position) and London (ranking third, with a loss of two positions) were able to confirm their leading position; the second and fourth positions are held respectively by Bournemouth - gaining eight positions - and Wiltshire, moving up of sixteen positions. Bournemouth and Wiltshire provide significant examples of websites performing better in the scenario-based evaluation than other destinations' websites having an equal or even greater amount of indicators: Bournemouth had the same contents and functionalities score as Yorkshire, but Yorkshire lost six positions when evaluated for its website capability to respond to users' goals and tasks, while Bournemouth gained eight positions; again, a website like the one of Brighton, even though it is more complete in terms of indicators than Bournemouth, registered a worse performance in the scenariobased evaluation.

It is possible to state that a DMO website providing a limited number of information and functionalities can put efforts in making those contents relevant, accessible and useful in order to allow users to fulfill their online goals. The Contents and Functionalities is a mere quantitative methodology: two websites with the same amount of indicators do not necessarily provide the same type of contents and functionalities; a DMO website could provide 
contents that are more relevant for the fulfillment of goals than those provided by another website, consequently performing better in the scenario-based evaluation.

Destination managers should check not only the quantity of online contents they are providing to website visitors, but also their quality, relevance and accessibility.

\section{Conclusions}

This study provides insights about destinations' online communication in terms of contents and functionalities that are available on destination website and in terms of user experience. It provides Destination managers with two tools for investigating and evaluating the online communication strategy on their official websites: a quantitative tools - the contents and functionalities analysis - focusing on the quantity of information and services provided, and measuring the "completeness" of a destination website, and a more qualitative tool - the scenario-based evaluation - focusing on the quality and availability of those information and services.

Performing the two analyses, destination managers are able to understand the strengths and weaknesses of their websites in terms of quantity and quality of contents and functionalities, thus in terms of online communication: a large amount of information does not imply that those pieces of information are easily accessible for the end-users; at the same time, a website with few contents and functionalities could prove extremely useful for tourists needing specific information, and willing to perform specific tasks.

Following the guiding idea of the book "The Paradox of Choice - Why More Is Less" (Schwartz, 2003), it is possible to argue that destination managers should focus more on the quality of the destination website contents and functionalities more than on their quantity. It is here demonstrated that on the one hand, best websites in terms of contents and functionalities do not always serve users' needs; on the other hand, few websites demonstrated to be very well designed and to perform well in terms of goals served. Destination managers should improve their online communication starting from a user-driven goal-oriented reasoning, and not from pure technology reasoning. The use of scenarios and the involvement of end-users during the whole website production (Brink et 
al., 2002) stages may be a helpful starting point for tourism managers to orient their communication towards the end users and not to mirror (as often may be the case) internal organization.

\section{References}

Brinck, T., Gergle, D., \& Wood, S. D. (2002). Designing Web sites that work : usability for the Web. San Francisco: Morgan Kaufmann Publishers.

Buhalis, D. (1998). Strategic use of information technologies in the tourism industry. Tourism Management, 19(5), 409-421.

Buhalis, D. (2000). Marketing the competitive destination of the future. Tourism Management, 21(1), 97-116.

Buhalis, D. (2003). ETourism : information technology for strategic tourism management. Harlow, England: Financial Times Prentice Hall.

Buhalis, D., \& Law, R. (2008). Progress in information technology and tourism management: 20 years on and 10 years after the Internet-The state of eTourism research. Tourism Management, 29(4), 609-623.

Buhalis, D., \& Spada, A. (2008). Destination Management Systems: Criteria for Success: An Exploratory Research. Journal of Information Technology \& Tourism, 3(1), 41-58.

Cantoni L., Faré M., Bolchini D., Inversini A., Giulieri F. (2007). European Cities and Web Tourism Communication, An Indicators-based Pilot Study. Proceedings of the Travel Distribution Summit, Europe, Research Conference, Axon Imprint, London, pp. 45-54

Cantoni, L., \& Tardini, S. (2006). Internet. London; New York: Routledge.

Carroll, J. M. (2000). Making use : scenario-based design of human-computer interactions. Cambridge, Mass.: MIT Press.

Choi, S., Lehto, X. Y., \& Oleary, J. T. (2007). What does the consumer want from a DMO website? A study of US and Canadian tourists' perspectives. International Journal of Tourism Research, 9(2), 59-72. 
Dix, A., Finlay, J. E., Abowd, G. D., \& Beale, R. (2003). Human-Computer Interaction (3rd ed.). Prentice Hall. Doolin, B., Burgess, L., \& Cooper, J. (2002). Evaluating the use of the Web for tourism marketing: a case study from New Zealand. Tourism Management, 23(5), 557-561.

Essawy, M. (2006). Testing the usability of hotel websites: the springboard for customer relationship building. Information Technology \& Tourism, 8(1), 47-70.

Frew, A. J., \& O’Connor, P. (1999). Destination marketing system strategies in Scotland and Ireland: an approach to assessment. Information Technology and Tourism, 2(1), 3-13.

Geest, T. van der. (2001). Web site design is communication design. John Benjamins Publishing Company. Gretzel, U., Fesenmaier, D. R., \& O'Leary, J. T. (2006). The transformation of consumer behaviour. Tourism Business Frontiers: Consumers, Products and Industry, 9-18.

Gretzel, U., Yuan, Y.-L., \& Fesenmaier, D. R. (2000). Preparing for the New Economy: Advertising Strategies and Change in Destination Marketing Organizations. Journal of Travel Research, 39(2), 146-156.

Horan, P., \& Frew, A. (2007). Destination Website Effectiveness - A Delphi-Based eMetric Approach - A DMS Perspective. Conference papers. Retrieved from http://arrow.dit.ie/tfschmtcon/7

Inversini, A. (2011). Cultural Destinations' Online Communication and Promotion: Discovering Official and Unofficial Online Sources Peculiarities of Cultural Destinations Promotion. LAP LAMBERT Academic Publishing.

Inversini, A., \& Cantoni, L. (2009). Cultural Destination Usability: The Case of Visit Bath. In W. Höpken, U. Gretzel, \& R. Law (Eds.), Information and Communication Technologies in Tourism 2009 (pp. 319-331). Vienna: Springer Vienna.

Inversini, A., Brülhart, C., \& Cantoni, L. (2012). Myswitzerland.com: Analysis of Online Communication and Promotion. Information Technology \& Tourism, 13(1), 39-49.

Inversini, A., Cantoni, L., \& Buhalis, D. (2009). Destinations' Information Competition and Web Reputation. Information Technology \& Tourism, 11(3), 221-234. 
Ip, C., Law, R., \& Lee, H. “Andy." (2011). A review of website evaluation studies in the tourism and hospitality fields from 1996 to 2009. International Journal of Tourism Research, 13(3), 234-265.

Jang, S. C. (2004). The past, present, and future research of online information search. Journal of Travel \& Tourism Marketing, 17(2/3), 41-47.

Law R, Qi S, Buhalis D. (2010). Progress in tourism management: a review of website evaluation in tourism research. Tourism Management 31(3): 297-313.

Law, R., \& Hsu, C. H. C. (2006). Importance of Hotel Website Dimensions and Attributes: Perceptions of Online Browsers and Online Purchasers. Journal of Hospitality \& Tourism Research, 30(3), 295-312.

Lee, J., \& Morrison, A. M. (2010). A comparative study of web site performance. Journal of Hospitality and Tourism Technology, 1 (1), 50-67

Lizzi, G, Cantoni, L. Inversini, A. (2011) When a Magazine Goes Online: A Case Study in the Tourism Field. In R. Law, M. Fuchs \& Francesco Ricci (Eds.), Information and Communication Technologies in Tourism 2011 Proceedings of the International Conference in Innsbruck, Austria(pp. 355-366). Wien: Springer.

Mills, J. E., \& Law, R. (2005). Handbook of Consumer Behavior, Tourism, and the Internet. New York; Florence: Routledge Taylor \& Francis Group

Morrison, A. M., Taylor, J. S., \& Douglas, A. (2004).Website evaluation in tourism and hospitality: the art is not yet stated. Journal of Travel \& Tourism Marketing, 17(2/3), 233-251.

Murphy, J., Forrest, E. J., \& Wotring, C. E. (1996). Restaurant marketing on the world wide web. Cornell Hotel \& Restaurant Administration Quarterly, 37(1), 61-71.

Murphy, J., Olaru, D., Schegg, R., \& Frey, S. (2003). The bandwagon effect: Swiss hotels' web-site and e-mail management. Cornell Hotel and Restaurant Administration Quarterly, 44(1), 71-87.

Nielsen, J. (2006). Severity Ratings for Usability Problems. Available online: http://www.useit.com/papers/heuristic/severityrating.html. Last access: April, 2012.

O'Connor, P., \& Frew, A. J. (2004). An evaluation methodology for hotel electronic channels of distribution. International Journal of Hospitality Management, 23(2), 179-199. 
Pan, B., \& Fesenmaier, D. R. (2006). Online Information Search: Vacation Planning Process. Annals of Tourism Research, 33(3), 809-832.

Qi, S. S., Law, R., \& Buhalis, D. (2008). Usability of Chinese destination management organization websites. Journal of Travel \& Tourism Marketing, 25(2), 182-198.

Schwartz, B. (2003). The Paradox of Choice: Why More Is Less (1st ed.). Harper Perennial.

Stepchenkova,S., Tang,L., Jang, A.P. Kirilenko,S.C., Morrison, A.M.(2010) Benchmarking CVB website performance: spatial and structural patterns Tourism Management, 31 (5), pp. 611-620

Triacca, L., Inversini, A., \& Bolchini, D. (2005). Evaluating Web usability with MiLE+. Seventh IEEE International Symposium on Web Site Evolution, 2005. (WSE 2005) (pp. 22- 29). Presented at the Seventh IEEE International Symposium on Web Site Evolution, 2005. (WSE 2005), IEEE.

UNWTO, W. T. O. (2001). E-Business for Tourism - Practical Guidelines for Destinations and Businesses. (W. T. Organization, Ed.). World Tourism Organization (UNWTO).

Wang, Y. (2008). Web-based destination marketing systems: assessing the critical factors for management and implementation. International Journal of Tourism Research, 10(1), 55-70.

Wang, Y., \& Fesenmaier, D. R. (2006). Identifying the Success Factors of Web-Based Marketing Strategy: An Investigation of Convention and Visitors Bureaus in the United States. Journal of Travel Research, 44(3), 239-249.

Werthner, H., \& Klein, S. (1999). Information Technology and Tourism - A Challenging Relationship (1st ed.). Springer.

Xiang,Z., K. Wöber,K., Fesenmaier, D.R. (2008) Representation of the online tourism domain in search engines Journal of Travel Research, 47 (2) (2008), pp. 137-150 
[FIGURE 1]

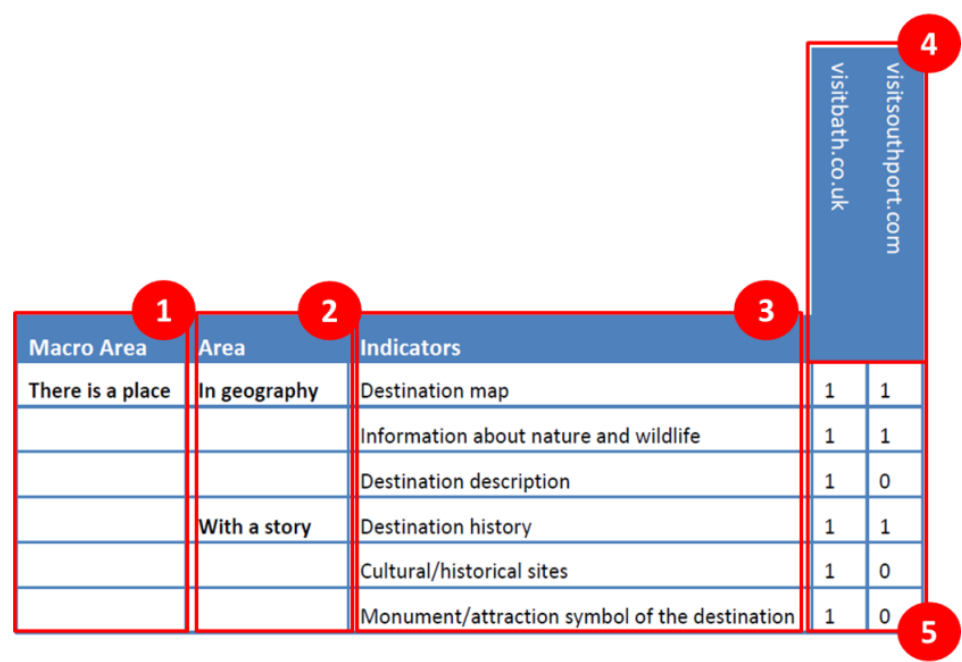

Figure 1: Content and Functionality Grid Organization

[TABLE 1] 


\begin{tabular}{|l|r|}
\hline Indicator & Frequency \% \\
\hline Places of interests & 99.2 \\
\hline List of attractions & 99.2 \\
\hline Hotels & 97.5 \\
\hline Attractions descriptions & 97.5 \\
\hline List of accommodations & 96.7 \\
\hline List of events & 96.7 \\
\hline Activities and Things to do & 95.8 \\
\hline Destination map & 94.2 \\
\hline Destination description & 93.3 \\
\hline Cultural/historical places & 93.3 \\
\hline
\end{tabular}

Table 1: Indicators frequency

[FIGURE 2]

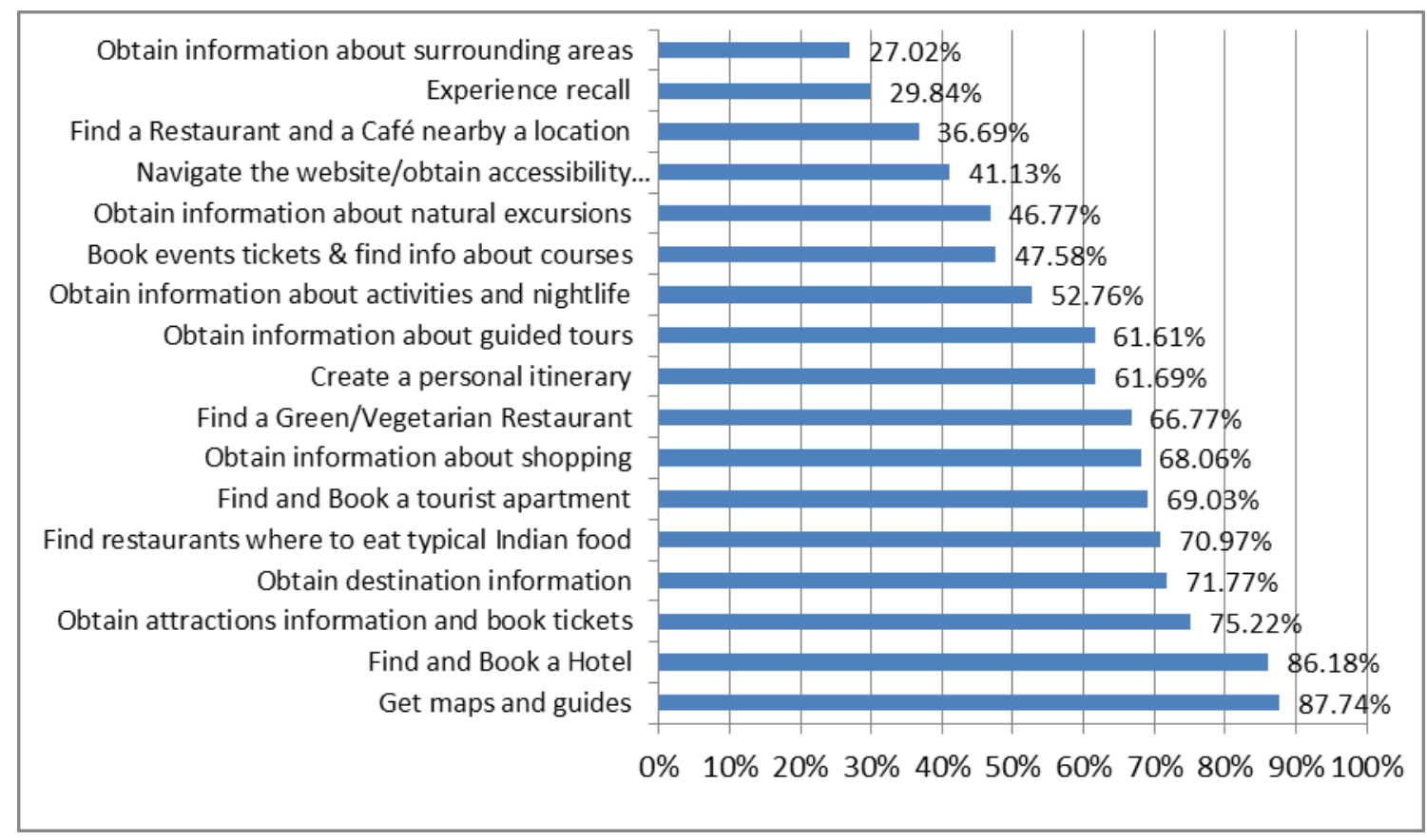

Figure 2: scenarios goals' ranking 
[TABLE 2] 


\begin{tabular}{|c|c|c|c|c|c|}
\hline Destination & C\&F score & Rank & Scenario-based & Rank & Change in the ranking \\
\hline London & 50 & 1 & 36.24 & 3 & $(-) 2$ \\
\hline Blackpool & 45.29 & 2 & 37.71 & 1 & $(+) 1$ \\
\hline Brighton & 44.21 & 3 & 33.67 & 9 & $(-) 6$ \\
\hline Lancashire & 42.03 & 4 & 33.82 & 8 & $(-) 4$ \\
\hline Bath & 42.03 & 4 & 32.57 & 12 & $(-) 8$ \\
\hline Bristol & 42.03 & 4 & 35.65 & 5 & $(-) 1$ \\
\hline Cornwall & 41.67 & 7 & 30.25 & 18 & $(-) 11$ \\
\hline Devon & 41.31 & 8 & 29.41 & 21 & $(-) 13$ \\
\hline Newcastle Gateshead & 39.5 & 9 & 35.63 & 6 & $(+) 3$ \\
\hline Bournemouth & 38.77 & 10 & 36.25 & 2 & $(+) 8$ \\
\hline Yorkshire & 38.77 & 10 & 31.15 & 16 & $(-) 6$ \\
\hline Hampshire & 36.96 & 12 & 25.51 & 28 & $(-) 16$ \\
\hline Winchester & 36.23 & 13 & 31.87 & 14 & $(-) 1$ \\
\hline Windsor and Maidenhead & 36.23 & 13 & 32.34 & 13 & $(=)$ \\
\hline York & 35.51 & 15 & 30.11 & 19 & $(-) 4$ \\
\hline Liverpool & 34.79 & 16 & 33.23 & 10 & $(+) 6$ \\
\hline Peak District and Derbyshire & 34.42 & 17 & 32.87 & 11 & $(+) 6$ \\
\hline North East England & 34.06 & 18 & 31.16 & 15 & $(+) 3$ \\
\hline The English Riviera & 34.06 & 18 & 25.51 & 29 & $(-) 11$ \\
\hline South East England & 33.7 & 20 & 28.44 & 23 & $(-) 3$ \\
\hline Wiltshire & 33.7 & 20 & 35.67 & 4 & $(+) 16$ \\
\hline Cambridge & 33.7 & 20 & 33.93 & 7 & $(+) 13$ \\
\hline Middlesbrough & 32.97 & 23 & 26.8 & 27 & $(-) 4$ \\
\hline Lincolnshire & 32.97 & 23 & 28.25 & 24 & $(-) 1$ \\
\hline Leicestershire & 32.97 & 23 & 28.55 & 22 & $(+) 1$ \\
\hline County Durham & 32.25 & 26 & 27.15 & 26 & $(=)$ \\
\hline Isle of Wight & 31.52 & 27 & 25.43 & 30 & $(-) 3$ \\
\hline Tunbridge Wells & 31.52 & 27 & 27.67 & 25 & $(+) 2$ \\
\hline Leeds & 31.52 & 27 & 29.73 & 20 & $(+) 7$ \\
\hline Essex & 31.52 & 27 & 30.78 & 17 & $(+) 10$ \\
\hline Birmingham & 31.52 & 27 & 22.51 & 31 & $(-) 4$ \\
\hline
\end{tabular}

Table 2: Comparison between Content and Functionality Analysis and Scenario Based User Experience analysis 